\title{
Building IT Capability to Increase Organizational Performance: A Path-Oriented Process
}

\author{
Rui Bi \\ School of Management \\ RMIT University, Melbourne, Australia \\ rui.bi@rmit.edu.au \\ Booi Hon Kam \\ School of Business IT and Logistics \\ RMIT University, Melbourne, Australia \\ booi.kam@rmit.edu.au \\ Kosmas X. Smyrnios \\ School of Management \\ RMIT University, Melbourne, Australia, \\ kosmas.smyrnios@rmit.edu.au
}

\begin{abstract}
Most studies on information technology (IT) capability have drawn their conceptualization from the tenets of resource-based view (RBV). Though path dependence is central to the concept of $R B V$, very few studies have examined the developmental paths of IT capabilities, which are typically treated as first-order constructs with their effects on firm performance investigated as direct causal links. This paper conceptualizes IT capability as the outcome of a path-specific resource building process, driven by the e-business skills and knowledge of a firm's IT human resources, which we refer to as e-business centric IT expertise. We posit that through the use of appropriate IT infrastructure, and the development of back-end integration and front-end functionalities, e-business centric IT expertise could be harnessed to provide the right information to the right customers at the right time, giving rise to a firm-specific IT capability. We further contend that IT capability is a source of competitive advantage, offering inimitable differentiation in market responsive agility, which is a key to securing sales in an increasingly customer-centric market. We operationalize these conceptualizations as a structural equation model (SEM) and tested 12 hypothesized relationships using data drawn from a survey of 310 fast-growth smallto-medium sized companies in Australia. The test results uphold 10 of the 12 formulated hypotheses, supporting our conceptualization that IT capability building is a path-specific process. To affirm our contention that IT capability is developed from the interacting effects of a suite of IT resources, and not the sum of the disjointed effects of individual resources, we also formulated and tested an alternative model that links individual IT resources directly to market responsive agility. Combined with a series of mediation tests, our SEM exercises confirm that IT resources interact in a specific way to give rise to IT capability to enhance market responsive agility and achieve sales performance. We discuss the implications of these findings in the context of IT investment.
\end{abstract}

Keywords: IT capability, E-business centric it expertise, Market responsive agility, Sales performance, Path-specific process 
Building IT Capability to Increase Organizational Performance: A Path-Oriented Process / Bi et al.

\section{Introduction}

It has been widely acknowledged that investments in information technology (IT) infrastructure and resources, if appropriately targeted, could engender valuable business outcomes (Barua and Mukhopadhyay, 2000). Part of the argument is that IT investment is a precursor to developing agile and flexible ITbased business or operation processes, which have been found to have a positive effect on firm performance, be it measured in terms of Tobin's q (Bharadwaj et al., 1999), equity market capitalization (Brynjolfsson and Hitt, 2000), stock price changes (Dehning et al., 2003), return on assets and return on sales (Dehning et al., 2007) or process-level improvements (Dong et al., 2009). There is, however, the counter argument that IT has become a ubiquitous resource (Carr, 2003), implying that IT investment would no longer generate competitive advantage. The debate on the effectiveness of IT investment has since raged on, with many studies arguing that the nature of the IT investment has to be differentiated when examining the effects of IT investment on firm performance (e.g., Bhatt and Grover, 2005; Brynjolfsson and Hitt, 1998).

There has since been a flood of information systems (IS) studies designed to explore the effects of e-business capability and IT usage on firm performance (e.g., Wu et al., 2003, Zhu, 2004, Zhu and Kraemer, 2002, Zhu and Kraemer, 2005). The conceptual base of many of these studies largely focuses on the development of IT capabilities, contending that it is the dissimilar means that firms employ to build their IT capabilities that differentiate their performance, despite having comparable IT resources (Bharadwaj, 2000; Wade and Hulland, 2004). As Bharadwaj (2000) rationalized:

Firms that achieve competitive advantage through IT have ... learned to combine effectively their IT resources to create an overall IT capability (p. 176).

Despite this recognition, many studies, which examine the effects of IT capabilities on firm performance, essentially treated IT capabili- ties as first-order constructs, and examined the effects of these constructs on firm performance as direct causal links (e.g., Bharadwaj, 2000; Fink and Neumann, 2007; Zhu, 2004; Zhu and Kraemer, 2005). Most of these studies also drew on the resource-based view (RBV) of the firms (Barney, 1991) to conceptualize the definition of IT or IS capabilities. Though path dependence is central to the concept of RBV (Teece et al., 1997; Eisenhardt and Martin, 2000; Helfat and Peteraf, 2003; Teece, 2007), very few studies have examined the developmental paths of IT capability (Bhatt and Grover, 2005), i.e., the structural linkages between the individual IT resources that collectively constituted the rent-generating IT resource bundle to produce IT capability.

The lack of focus on conceptualizing IT capability as a network of constructs is a significant gap in IS literature. The manner in which IT resources are combined to form IT capability is central to the resource-building paradigm of RBV (Makadok, 2001; Ravinchandran and Lertwongsatien, 2005). Ignoring the structural linkages between different IT resources in the modelling of IT capability means that the differential role, and hence effect (both direct and indirect), of individual IT resources in building IT capability would not be distinguishable. From an IT investment perspective, this implies that the investment return of individual IT resources could not be appropriately gauged.

This study attempts to fill that gap by conceptualizing IT capability as the outcome of a path-specific resource building process. By so doing, we argue that organizations gain competencies and competitive advantages through a capability building process based on resource availability. This approach conforms with Bharadwaj's (2000) conception of IT capability, which suggests that not all IT resources will have a direct effect on firm performance. The manner in which discrete IT resources interact with one other to give rise to IT capability is the subject of investigation in this study and a contribution to the IS literature. 
Building IT Capability to Increase Organizational Performance: A Path-Oriented Process / Bi et al.

In conceptualizing the causal linkages between different IT resources, we extend the e-business capability construct of Zhu (2004) and Zhu and Kraemer (2005) and develop a framework that views IT capability as a network of constructs driven by the e-business skills and knowledge of a firm's IT personnel, which we refer to as e-business centric IT expertise. Through the use of appropriate IT infrastructure, and the development of backend integration and front-end functionalities, e-business centric IT expertise could be harnessed to provide the right information to the right customers at the right time, giving rise to a firm-specific IT capability. Because of the firm-specific characteristics of IT capability, we further argue that organizational support, in particular top management commitment (TMC) toward IT use and e-business development, is critical to nurturing this IT capability.

One of the main advantages generated by a firm's IT capability is its ability to provide upto-date information to the focal firm to enable it to respond speedily to changing market situations (Wu et al., 2006). We view this ability as market responsive agility, a manifestation of the value of IT investment, which augments firm performance. We developed 12 hypotheses associated with the above conceptualized framework to form a structural equation model (SEM) and tested them empirically using data drawn from a survey of 310 fast-growth small-to-medium enterprises (SMEs) in Australia.

Our focus on fast-growth SMEs is another major contribution to the IS literature, as very few systematic empirical work has been done in examining the factors contributing to building IT capability and e-business competency in SMEs (Eikebrokk and Olsen, 2007; Raymond and Bergeron, 2008). The general contention has been that SMEs lack the financial means and IS resources to develop their IT capability and e-business competency (Johnston et al., 2007). Because of their limited IS resources, the way SMEs build their IT capabilities could also differ substantially from those of their larger, or better resourceendowed, counterparts (Eikebrokk and Olsen,
2007). Limiting our sample to fast-growth SMEs gives further unique insights into the way high achieving SMEs utilize their IT resources to build IT capability.

To reinforce our contention that IT capability is developed from the interacting effect of a suite of IT resources, and not the sum of the disjointed effects of individual resources, we formulated and tested an alternative model that links individual IT resources directly to market responsive agility. Through a series of mediation tests, our SEM exercises confirm that IT resources interact in a specific way to give rise to IT capability to enhance market responsive agility and achieve sales performance.

The confirmation of a causal structure linking different IT resources implies that each IT resource plays a specific role, as part of the resource bundle, in contributing to the development of IT capability. Our findings shed light on the IT investment paradox debate by suggesting that the effect of IT investment on the building of organizational capability hinges on the emphasis organizations give to the different IT related resources, such as IT infrastructure versus IT human resources versus back-end and front-end development. The strength of the IT capability generated from the bundle of IT resources depends not necessarily on the relative strength of the individual IT resources, but more on the synergistic effect created by their combination. For instance, investment in developing a very attractive front-end (such as incorporating more transactional functionalities) without a corresponding dose of funds given to expanding back-end capability to support the working of these functionalities could lead to a situation that suggests IT investment (in the front-end in this instance) is ineffective in enhancing market-responsive agility. Likewise, writing elegant software to develop a versatile backend for speedy information processing, for example, may not lead to an enhanced operation, if the IT infrastructure available was not capable of supporting the way information would be processed as the backend intended it to be. 
Building IT Capability to Increase Organizational Performance: A Path-Oriented Process / Bi et al.

The next section will present the conceptual framework that underlies our rationalization of the causal linkages between IT resources and their cumulative effects on a firm's market responsive agility and performance together with the 12 hypotheses that flow from those rationalizations. We then describe the data collection process and the results of the SEM exercise conducted to test the hypotheses. The last section discusses the findings, study contributions, limitations and directions for further research.

\section{Conceptual Framework and Hy- potheses}

Day and Wensley (1988) contend that "the creation and sustenance of a competitive advantage are the outcomes of a long-run feedback or cyclical process" (p. 2) underpinned by a simple, sequential source-positionperformance framework. Day and Wensley (1988) explain that superior skills, or skills that are rare and not easily or readily acquired on factor markets by competitors, are sources of advantages. In the context of ebusiness operations, the heterogeneous approaches firms developed internally to exploit and combine their IT resources to differentiate their service offerings constitute superior skills, which have been invariably referred to as IT capability (Bhatt and Grover, 2005; Bharadwaj 2000). At a more basic level, a firm's ability to discriminately invest in IT resources to build its IT capabilities that enable it to operate differently from its competitors is also a unique set of valuable skills that would be hard for others to imitate. In a general sense, IT capabilities would encompass skills that allow the firm to develop an IS that could integrate its firm-wide activities in a coordinated manner, enabling its personnel to not only operate more efficiently but also respond to customer needs and requests in ways different from its competitors. From the perspective of Swanson's (1994) IS innovation typology, such skills would encompass all three types of innovations: building task-oriented relational databases (Type I); applying IS to support a diverse range of administrative tasks (Type II); and integrating IS with core business functions throughout the value chain (Type III).

Because technical and managerial IT skills are typically developed over long periods of time through accumulated experience, and enriched progressively through learning-bydoing and routinization (Bhatt and Grover, 2005), the developmental paths of IT capability is socially complex and causally ambiguous (Bharadwaj, 2000). Time compression diseconomies (Dierickx and Cool, 1989) accentuate the immobility and inimitability of these socially complex processes, making it hard for such an organization-specific IT capability to be transferred to, or acquired by, competitors. From the perspective of RBV, IT capabilities are rent-generating resources (Bharadwaj, 2000; Wade and Hulland, 2004) and are a source of advantage.

Day and Wensley's (1988) source-positionperformance framework forms the conceptual base upon which our research model was constructed (see Figure 1). We contend that in a fast-changing e-business environment fuelled by rapid advances in IT infrastructure, firms with superior IT capability would be in an advantageous position to rapidly and flexibly react to market changes, including customer and supplier needs, evolving competitors' strategies, and new product development, to outperform competitors. Following Sambamurthy et al. (2003), we term this ability as market responsive agility, which is crucial to securing sales in an increasingly customer-centric market (Kim et al., 2006), a key business performance indicator.

Our primary focus, and main contribution, in this study is conceptualizing the development paths of IT capability from IT resources. Central to our conceptualization is the contention that a firm's capabilities are built from its resource configurations (Eisenhardt and Martin, 2000), underscored by the developmental path the firm took to exploit opportunities and neutralize threats by combining its resources in unique ways which render imitation by competitors difficult (Barney, 1991). To examine the process of building IT capability to create hard-to-imitate market responsive 


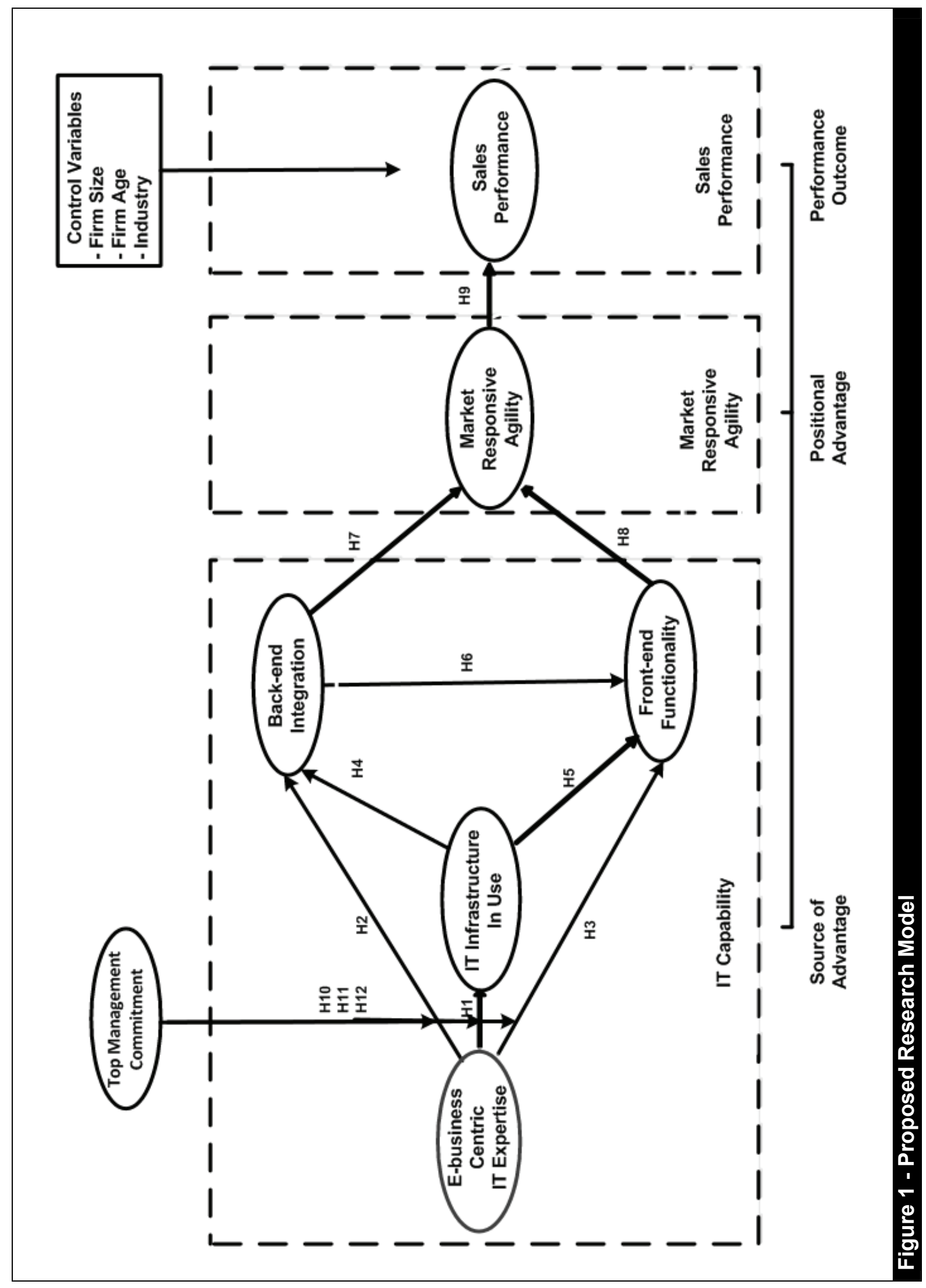


Building IT Capability to Increase Organizational Performance: A Path-Oriented Process / Bi et al.

agility, we argue that four sets of IT resources are indispensable: e-business centric IT expertise, IT infrastructure, back-end integration and front-end functionality.

\section{E-business centric IT expertise}

In e-business operations, two factors are fundamental to achieving market responsive agility - information readiness and information integration. Information readiness denotes a state of preparedness, supported by the availability of an integrated, comprehensive, business-useful database (information integration) that allows information to be readily mined and transformed into market intelligence. The two, as such, are closely intertwined. Information ready firms are also information integrated; they are strategically poised to initiate, adopt, and routinize ebusiness (Fink and Neumann, 2007).

For a firm to reach a stage of information readiness to become market responsive, two IT ingredients are paramount: IT infrastructure and IT human resources (Bharadwaj, 2000, Mata et al., 1995, Zhu and Kraemer, 2005). Given that IT infrastructure is fast becoming, if not already, a commodity (Clemons and Row, 1991; Zhu and Kraemer, 2005), information integration would not be adequately accomplished if a firm's IT personnel are not e-business astute (Ross et al., 1996). Indeed, the competitive advantage of firms in e-business operations is largely linked to the business judgment and technical skills of its IT human resources and top management (Armstrong and Sambamurthy, 1999, Bhatt and Grover, 2005, Sambamurthy et al., 2003). IT business experience is paramount in enabling a firm to align its IT strategy to its business strategy, and develop information-rich and cost-effective applications for the business (Kearns and Lederer, 2003). Further, firms having IT personnel with superior knowledge about business strategy, competition, and market opportunities are better able to continue to improve their market agile capability through a process of experiential learning (Bhatt and Grover, 2005; Cohen and Levinthal, 1990).
IT personnel, therefore, must possess the requisite IT skills to develop effective ebusiness applications systems. Additionally, IT personnel must command the e-business knowledge and experience to understand the requisite information needed to develop and support the applications systems to build long-term competitive advantage (Clark et al., 1997), a premise that underpins the mutually reinforcing nature of physical IT assets and IT human resources (Bharadwaj, 2000; Mata et al., 1995; Zhu and Kraemer, 2005). We develop a construct - e-business centric IT expertise - to capture the presence of such knowledge in an organization.

\section{IT infrastructure}

While IT human resources are the seeds of knowledge and skills that generate innovative e-business applications, IT infrastructure, despite having become a commodity, is still an indispensable platform for e-business development. Lin and Lin (2008) and Zhu and Kraemer (2005) have also shown that the effects of IT infrastructure on IS performance hinge largely on the level of sophistication of the IT infrastructure employed. Zhu et al. (2003) also argue that e-business is unlikely to become an integral part of the value chain if firms lack appropriate IT infrastructure, on which necessary information for e-business operations can be readily and efficiently distributed.

\section{Back-end integration and front-end functionality}

The information-intensive nature of ebusiness suggests that the value contributions of IT capability in e-business lies in providing visibility, traceability, and real-time information (Sanders, 2008). The prowess of this contribution hinges primarily on two IS development outcomes: how well different databases are integrated to enable crossfunctional and multi-layer querying (back-end integration); and how well the cross-functional and multi-layer linkages are transformed into a user-friendly, easy-to-use, customer-centric operations system (front-end functionality) (Zhu, 2004). Through usage, a welldeveloped back-end with extensive database 
Building IT Capability to Increase Organizational Performance: A Path-Oriented Process / Bi et al.

integration capabilities manifested through superior front-end functionalities or a set of well-contrived, customer-centric front-end functionalities backed by a technically sound back-end will improve transactional efficiencies, lower operation costs, and create business value (Zhu and Kraemer, 2005). Zhu (2004) and Zhu and Kreamer (2005) contend that creating synergistic effects through the integration of front-end e-commerce capability and back-end IT infrastructure is a tangible path to raising e-business value. Hence, back-end integration and front-end functionality are important value-generation components of e-business operations. The synergistic operations of back-end integration and front-end functionality constitute the bed rock of a firm's IT capability.

\section{IT capability development}

Taken together, the four constructs - ebusiness centric IT expertise, IT infrastructure in use, back-end integration and front-end functionality - constitute a "mechanism" within which a firm's IT capability could be developed to create value to support e-business operations. E-business centric IT expertise will provide the seed of growth for information readiness and information integration, shaping the information content and the way in which information is to be created and used; back-end integration will provide the enabler for information processing, integration and coordination to facilitate cross-functional and multi-layer querying to support market responsive agility; front-end functionalities will serve as the conduit for information exchange between the focal firm and value chain members, including customers; and IT infrastructure in use will provide the platform for the development of back-end and front-end, enabling them to nurture and maintain market responsive agilities.

In sum, IT capability development would involve leveraging available IT skills and ebusiness knowledge (e-business centric IT expertise) to harness appropriate IT infrastructure (IT infrastructure in use) to develop a technology-enabled, task-oriented back-end for information integration, sharing, and ac- cess (back-end integration) and a userfriendly front-end with multi-faceted functionalities (front-end functionality). From a structural perspective, this view leads us to the following three hypotheses concerning the direct effects of e-business centric IT expertise on IT infrastructure in use, back-end integration, and front-end functionality:

H1: E-business centric IT Expertise will contribute positively to the identification, selection, and use of appropriate IT infrastructure (IT infrastructure in use).

H2: E-business centric IT Expertise will contribute positively to the building of backend integration.

H3: E-business centric IT expertise will contribute positively to the development of front-end functionality.

Lewis (2001) argues that inter-firm channel systems permit "large scale tracking of customer preferences" (p. 7), which suggests that firms with stronger channel capabilities are more able to promote information exchange, undertake information coordination activities, and be more capable of meeting customer information requirements. Zhu et al. (2004) and Zhu and Kraemer (2005) have also shown that firms using advanced IT infrastructure (e.g., extranet) to communicate with customers and business associates have increased chances of integrating its databases at the back-end and creating an effective, user-friendly set of functionalities at its front-end. Additionally, through the mediating role of IT infrastructure in use, e-business centric IT expertise also exerts an indirect effect on back-end integration and front-end functionality, giving the following two hypotheses:

H4: IT infrastructure in use enhances backend integration.

H5: IT infrastructure in use enhances frontend functionality.

Back-end integration is an integral component of a customer-centric information agile operation vital to establishing seamless linkages among heterogeneous databases that 
Building IT Capability to Increase Organizational Performance: A Path-Oriented Process / Bi et al.

make information accessing and querying user-friendly (Zhu et al., 2004). A wellintegrated back-end is a precursor to developing innovative data query algorithms that could provide unusual insights into the relational potentials of available information. Consequentially, a well-integrated back-end has the capability to foster intra- and interorganizational connectivity (Zhu et al., 2004), promote information transparency (Dong et al., 2009), increase business degrees of freedom (Bharadwaj, 2000, Keen, 1991), enhance coordination efficiency, and improve process performance (Zhu and Kraemer, 2005). The tight connection between frontend functionalities and back-end processes in an e-business platform assures consistent information service quality for customers. Thus,

H6: Higher levels of back-end integration will enhance the efficacy of front-end functionalities.

From the perspective of creating an inimitable source of advantage (Day and Wensley, 1988), this interrelated view of the four IT resource constructs implies that IT capability is developed through a causally complex network of resource bundle driven by e-business centric IT expertise. Such a network premise of IT capability development is consistent with the notion that capabilities are rooted in processes and business routines (Day, 1994).

\section{IT capability and market responsive agility}

Seamless connectivity between disparate databases made possible by back-end integration enables a firm not only to flexibly align its operational processes in response to customer needs and preferences, but also to alter its business strategies to leverage the resources of value chain partners, and to adapt to market conditions and evolving customer demands in line with competitive pressures (i.e., market responsive agility). Radjou (2003), for instance, reports that US manufacturers relied on their IT resources and IS capabilities to increase their supply chain agility, reduce cycle time, achieve greater operational efficiency, and deliver products to customers in a timely manner. From a functional perspective, back-end integration has the potential to increase a firm's market responsive agility to create e-business value (Zhu, 2004). Accordingly, we postulate that:

H7: Back-end integration is related positively to market responsive agility.

Front-end functionalities enable firms to provide real-time product and service information to customers and facilitate customer selfservice of online account management (Zhu and Kraemer, 2002, Zhu and Kraemer, 2005). Personable interactive front-end functionalities are user-friendly communication systems that attract explorations by customers. They are potent sources of customer agility, providing the requisite information for firms to realign their databases to provide timely response to customer needs through on-time delivery, efficient ordering procedures, customer alertness (Stank et al., 2001), and general market responsiveness (HernándezEspallardo and Arcas-Lario, 2003). A firm could not achieve market responsive agility without the support of a customer-responsive, user-friendly front-end in an e-business environment. Further, firms embedding personalized and integrated customer services in their front-end functionality are more information agile than competitors that do not offer such services (Zhu et al., 2004). This rationale provides the conceptual base for our next hypothesis:

H8: Front-end functionality has a positive effect on market responsive agility.

\section{Market responsive agility and sales performance}

As some business studies have demonstrated (e.g., Kim et al., 2006, Wu et al., 2006), market responsive agility is one of the key determinants of organizational performance. In this exploratory study, we use sale performance as a measure of firm performance and formulate the following hypothesis on the premise that market responsive agility could widen a firm's market outlets, and increase its sales volume, thus expanding its market shares: 
H9: Market responsive agility augments sales performance.

\section{The role of top management commit- ment}

Competitive IT capabilities are dynamic. They require constant renewal. A supportive organizational culture is vital in nourishing such capabilities (Teece, 2007). Among various organizational factors, such as firm size, organizational structure, corporate culture, firm location and industry, that have been found to affect IT capabilities, TMC has been singled out by Wade and Hulland (2004) as a key potential moderator. Wade and Hulland (2004) contend that a firm could derive competitive advantage from strategic IT use with top management support, lack of which the effect that IS resources have on a firm's competitive position or performance quickly diminishes, even if substantial investments are made to strengthen such resources. Chatterjee et al. (2002) also note that the IT literature is not short of studies that stress the importance of top management support for IT assimilation. Formulating a construct with seven items focusing on top management's understanding of e-business role and support for e-business development within firm, we posit that strong TMC would enhance the effects that ebusiness centric IT expertise has on IT infrastructure use, back-end integration, and frontend functionality, giving us three further hypotheses:

H10: TMC enhances the link between ebusiness centric IT Expertise and Backend Integration.

H11: TMC enhances the link between ebusiness centric IT Expertise and IT Infrastructure in Use.

H12: TMC enhances the link between ebusiness centric IT Expertise and Frontend Functionality.

\section{Control Variables}

Because the dependent variable in our structural model is sales performance, which is a function of many organizational factors, we included three control variables in our SEM exercise: firm size, age, and industry. Firm size reflects the strength of an organization's resources and has a significant impact on innovation (Cooper and Zmud, 1990, Damanpour, 1991, Rogers, 1995). It could also be a competitive advantage ( $\mathrm{Wu}$ et al. 2003; Mishra and Agarwal, 2009; Dong et al., 2009) as larger business units typically have greater access to a more extensive range of financial resources (Rogers, 1995) and thus are more able to invest in sales-generating resources. We used number of employees as a measure of firm size in our model.

Like firm size, firm age can also affect firm performance. With a longer history of market appearance than their younger counterparts, established firms tend to have strong relational networks with business partners, financial institutions, communities, government, and consumers (Dobbs and Hamilton, 2007). Old firms also have more time to perfect their business processes, the opportunity to learn from their experiences (Fichman, 1992) and to gain a reputation for their products and services in selected markets (Dobbs and Hamilton, 2007), all of which can impact current firm performance. In this study, we measured firm age by the number of years of business start-up.

The inclusion of industry stems from possible differing operational practices and buyersupplier dynamics across industries, which could potentially influence the extent to which firms use e-commerce (Mishra and Agarwal, 2009). We used a dummy variable, separating responding firms into IT or non-IT industry, to assess its effect on sales performance.

The 12 formulated hypotheses are accordingly indicated in Figure 1.

\section{Research Method}

\section{Sampling and Data Collection}

The data used for testing our proposed model was collected through an online survey of 1,335 Australian fast-growth companies selected from the Business Review Weekly (BRW) fast-growth SME file. The BRW fastgrowth SMEs are similar to Fortune's FSB 100 annual list of North America's fastest 
Building IT Capability to Increase Organizational Performance: A Path-Oriented Process / Bi et al.

growing small companies. SMEs wanting to be listed on the BRW fast-growth project must record a revenue growth rate in excess of $10 \%$ per annum for the last three years, achieve an annual turnover in excess of AUD $\$ 500,000$ during the previous year, have fewer than 200 full-time employees, are not a subsidiary of an Australian or overseas corporation, and receive no more than $50 \%$ of their revenue from a single client.

We tested our model using SMEs because IT research on SMEs is still thin on the ground and the benefits SMEs derive from IT is far from conclusive (Eikebrokk and Olsen, 2007; Johnston et al., 2007; Raymond and Bergeron, 2008). There is also the stereotype view that SMEs lack the financial resources and IS expertise to take advantage of the power of advanced IT infrastructure to generate competitive advantage (Kuan and Chau, 2001; Thong, 1999). Therefore, we narrow our focus to fast-growth SMEs to examine how an elite group of SMEs develop their IT capability to achieve market responsive agility and gain sales growth. In a slightly different vein, the focus on fast-growth SMEs also lend support to the choice of sales growth as a performance measure, since revenue growth is the primary indicator of business growth BRW uses to select its fast-growth SMEs.

A personalized email highlighting the academic nature of the study was sent to either the founder or CEO of all 1,335 fast-growth SMEs listed on the BRW database. In our emails, we emphasized the importance of having respondents with a good understanding and overview of their firm's e-business activities in our survey, urging the founder or CEO to personally complete the online questionnaire. A follow-up email was sent three weeks after the initial one, and a second reminder email another two weeks later. Respondents were assured of confidentiality. A total of 310 valid responses were received. Excluding 195 incorrect email addresses and 35 companies which declined to participate, we achieved a $28.1 \%$ response rate.

Using the approach suggested by Armstrong and Overton (1977), we checked the data for non-response bias by comparing early (i.e., those responded upon our initial email invitation) and late (i.e., those responded after the follow-up emails) responses. Independent samples $t$-tests on each construct between early and late responders failed to reveal significant differences (all $p_{s}>.05$ ), suggesting that nonresponse bias was not a problem.

\section{Profile of Responding Companies}

The profile of the responding firms in our study (Table 1) shows that our sample contains companies in all major industry sectors. There is also equal distribution of companies in terms of their age (or years of establishment). More significantly, all questionnaires were completed by either the company founder or its CEO and that all responding firms had achieved a growth rate in excess of $20 \%$ in 2008 .

\section{Test for Common Methods Bias}

As our study used a self-administered questionnaire and respondents were in a senior management position qualified to assess firm performance, measurement was subject to cognitive biases due to participants "seeking to present themselves in a favorable manner" (Thompson and Phua, 2005). Anticipating such a possibility, we incorporated Marlowe and Crowne's (1961) Social Desirability Scale in our online questionnaire to collect information to enable us to assess all study items for social desirability response bias in order to address internal validity and psychometric aspects of instruments. Marlowe and Crowne's (1961) Social Desirability Scale has been used widely for checking cognitive biases (Ballard, 1992, Fraboni and Cooper, 1989).

In this study, we tested common method bias using SEM procedures recommended by Podsakoff et al. (2003). First, we conducted a Harman one-factor test to estimate the extent of the bias. Principal components analysis resulted in six components, accounting for $70.1 \%$ of the total variance. The first component explained only $37.1 \%$ of the variance, implying the absence of a dominant general factor that accounts for more than $50 \%$ of the variation. Second, this study controlled for the 
Building IT Capability to Increase Organizational Performance: A Path-Oriented Process / Bi et al.

effects of a directly measured social desirability factor (i.e., the social desirability factor was linked to all endogenous variables). Results culminated in a poor fitting model entailing associations between social desirability and model parameters, with all path coefficients being close to zero and nonsignificant (all $p_{\mathrm{s}}>$.05). Accordingly, social desirability is not an issue in our sample. Based on these tests, we conclude that common method bias is not a significant threat in our study.

\section{Constructs}

Development of respective measurement models incorporate successive stages of theoretical modeling, statistical testing, and refinement, as suggested by Straub (1989). Measurement items used in this study were adapted from previously validated measures or were developed on the basis of a literature review. E-business centric IT expertise was measured with items selected to reflect firm level e-business specific IT expertise (Lin and Lin, 2008, Thong, 1999). IT infrastructure in use was measured with items adapted from Zhu and Kraemer (2005), and Zhu et al.
(2004), focusing on telecommunications and database infrastructure. Back-end integration was measured with three items framed to represent the extent to which web applications are electronically integrated with backoffice, and the extent company databases are electronically integrated with suppliers and partners (Zhu and Kraemer, 2005). Frontend functionality was instrumented both by generic functionality, as well as by specific customized functionality. Generic front-end functionality was measured by three items adapted from Zhu and Kraemer (2005), representing ability of responding firms to support online sales, online transactions and information search. Specific customized frontend functionality was measured by four items adapted from Wu et al. (2003), and Zhu and Kraemer (2002), reflecting web-site features related to customer-oriented services. Because of the two distinctive sets of items used in its measurement, front-end functionality was conceptualized as a second-order construct.

\section{Table 1 - Profile of Responding Firms}

\begin{tabular}{|lc|}
\hline Industry & $\%(n=310)$ \\
Information Technology & 19.7 \\
Property \& Business Services & 18.7 \\
Personal \& Other Services & 9.0 \\
Finance \& Insurance & 8.4 \\
Communications & 7.4 \\
Others ${ }^{\text {a }}$ & 36.7 \\
\hline Company Age & 50 \\
Less than 5 years & 50 \\
More than 5 years & $21.9-759.5$ \\
\hline Previous Year Growth Rate & 55.2 \\
\hline CEO/Founder's Education Level & 15.8 \\
Tertiary & 14.5 \\
MBA & 1.6 \\
Year 12 & 12.9 \\
PhD or Doctorate & 5 \\
Other & \\
\hline
\end{tabular}

Note. ${ }^{a}$ Other industry sectors include Construction; Retail Trade; Manufacturing; Health and Community Services; Wholesale Trade; Education; Transport and Storage; Accommodation, Café, Restaurants; Mining; Cultural and Recreational Services. 
Building IT Capability to Increase Organizational Performance: A Path-Oriented Process / Bi et al.

Measures of market responsive agility were adapted from Wu et al. (2006) and Kim et al. (2006). Sales performance was measured using three items to indicate sales growth, market share, and market development. These items were adapted from Zhu and Kraemer (2005). Lastly, TMC was measured using seven items, adapted from Wu et al. (2003). The measures focused on top management's willingness and commitment to use ebusiness. All measures were rated using a seven-point Likert scale with anchors ranging from strongly disagree (1) to strongly agree (7). Table 2 lists the questionnaire items used to measure each construct.

\section{Instrument Validation}

Data were analysed using confirmatory factor analysis (CFA) procedures (AMOS 17.0) and involving a maximum likelihood (ML) estimation method. All constructs were tested for reliability, validity, and fit. Based on an assessment of CFA fit statistics, measurement models were further refined. Table 3 presents the correlations and descriptive statistics of the model constructs, while Table 4 indicates the measurement properties of constructs. Instrument validation proceeded through three steps: calculation of construct reliability, estimation of variance extracted, and evaluation of construct validity.

\section{Construct Reliability}

Construct reliability, a measure of consistency, assesses the degree to which items are free from random error. Indicator and composite reliability are two measures of construct reliability (Fornell and Larcker, 1981). While indicator reliability represents the proportion of variation that is explained by a construct it purports to measure, composite reliability reflects the internal consistency of indicators (Werts et al., 1974). In the present study, indicator reliability values range between .30 and .88 , and composite reliability values exceed the recommended value of .7 (Nunnally and Bernstein, 1994).

\section{Variance Extracted Estimate}

Variance extracted estimate reflects the overall amount of variance in indicators ac- counted for by a latent construct (Fornell and Larcker, 1981). In this study, all estimates exceed the recommended value of .5 (Hair et al., 2006).

\section{Construct Validity}

Construct validity was established by measuring convergent and discriminant validity of measurement items (Straub, 1989). Convergent validity assesses the consistency across multiple operationalizations. Values for $t$ statistics for all factor loadings are significant (all $p_{s}<.001$ ), indicating that measures satisfy convergent validity criteria (Gefen et al., 2000). According to Fornell and Larcker (1981), average variance extracted for each construct should be greater than the squared correlation between constructs when assessing for discriminant validity, the extent to which different constructs diverge from one another. Our results suggest that items share more common variance with related than non-related constructs, with all constructs meeting this criterion.

Confirmatory and full structural model fits were assessed using multiple indices (Hair et al., 2006), including the ratio of $X^{2}$ to degrees of freedom $\left(X^{2} / \mathrm{df}\right.$ ) (Jöreskog, 1978), comparative fit index (CFI), Tucker-Lewis Index (TLI), root mean-square error of approximation (RMSEA), and standardized root meansquare residual (SRMR). A $X^{2} / \mathrm{df}$ ratio of below 3 indicates sound fit (Carmines and Mclver, 1981). Values of CFI and TLI above .90 are considered good fit (Hair et al., 2006). A RMSEA of .08 or less indicates a close fit (Hair et al., 2006) and SRMR should be less than .06 (Hu and Bentler, 1999). All seven measurement models tested were found to meet these criteria.

\section{Validity of Front-end Functionality as a Reflective Second-Order Construct}

Petter et al. (2007) warn that a common problem among IS studies using SEM is the use of reflective construct specification, when formative measurement is more appropriate. To avoid the problem, the decision rules suggested by Jarvis et al. (2003) for identifying construct as formative or reflective were 


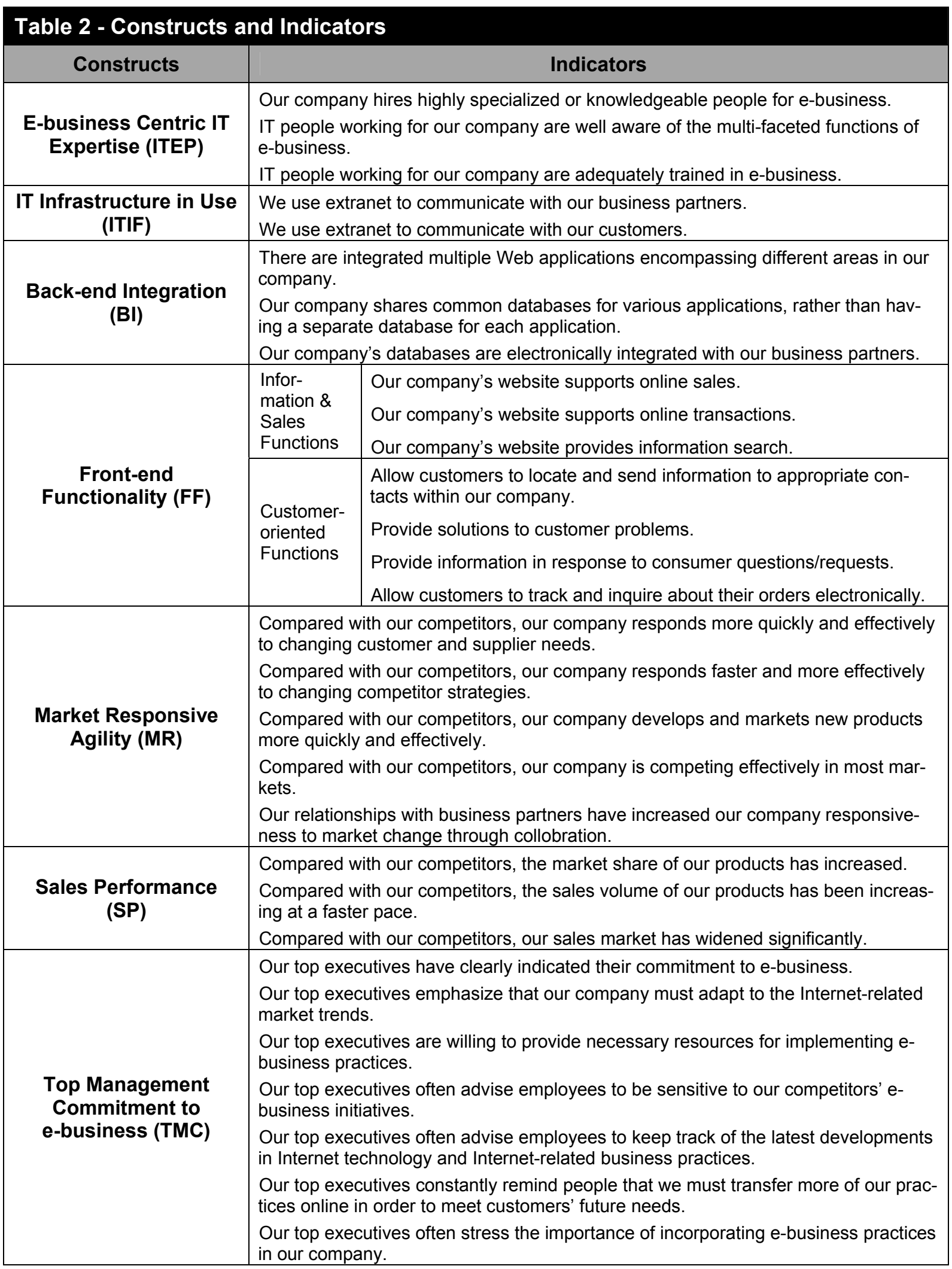




\begin{tabular}{|c|c|c|c|c|c|c|c|c|c|}
\hline Variables & Mean & SD & 1 & 2 & 3 & 4 & 5 & 6 & 7 \\
\hline 1. E-business Centric IT Expertise & 4.95 & 1.69 & 1 & & & & & & \\
\hline 2. IT Infrastructure in Use & 5.77 & 1.65 & $.23^{* *}$ & 1 & & & & & \\
\hline 3. Back-end Integration & 4.12 & 1.63 & $.52^{* *}$ & $.25^{* *}$ & 1 & & & & \\
\hline $\begin{array}{l}\text { 4. Information \& Sales Front-end } \\
\text { Functionality }\end{array}$ & 3.96 & 1.83 & $.37^{\star *}$ & $.17^{\star *}$ & $.46^{* *}$ & 1 & & & \\
\hline $\begin{array}{l}\text { 5. Customer-oriented Front-end Func- } \\
\text { tionality }\end{array}$ & 4.8 & 1.42 & $.49^{* *}$ & $.31^{* *}$ & $.54^{* *}$ & $.50^{* *}$ & 1 & & \\
\hline 6. Market Responsive Agility & 5.33 & 1.03 & $.34^{* *}$ & $.14^{*}$ & $.34^{* *}$ & $.34^{* *}$ & $.39^{* *}$ & 1 & \\
\hline 7. Sales Performance & 5.54 & 1.32 & $.29^{* *}$ & 0.11 & $.20^{* *}$ & $.28^{* *}$ & $.30^{* *}$ & $.58^{* *}$ & 1 \\
\hline
\end{tabular}

Note. ${ }^{*} p<.05 .^{* *} p<.01$.

\begin{tabular}{|l|c|c|c|c|c|}
\hline \multicolumn{1}{|c|}{ Table 4 - Confirmatory Factor Analysis } \\
\hline \multicolumn{1}{|c|}{$\boldsymbol{\alpha}$} & $\begin{array}{c}\text { Construct } \\
\text { Reliability }\end{array}$ & $\begin{array}{c}\text { Variance } \\
\text { Extraction }\end{array}$ & $\begin{array}{c}\text { Range of } \\
\text { Standardized } \\
\text { Loadings }\end{array}$ & $\begin{array}{c}\text { Range of } \\
\text { Indicator } \\
\text { Reliability }\end{array}$ \\
\hline 1. E-business Centric IT Expertise & 0.86 & 0.87 & 0.7 & $.76-.94$ & $.58-.88$ \\
\hline 2. IT Infrastructure in Use & 0.82 & 0.78 & 0.64 & $.79-.90$ & $.61-.81$ \\
\hline 3. Back-end Integration & 0.75 & 0.74 & 0.5 & $.64-.81$ & $.41-.66$ \\
\hline $\begin{array}{l}\text { 4. Information \& Sales Front-end } \\
\text { Functionality }\end{array}$ & 0.78 & 0.8 & 0.57 & $.55-.88$ & $.30-.77$ \\
\hline $\begin{array}{l}\text { 5. Customer-oriented Front-end Func- } \\
\text { tionality }\end{array}$ & 0.74 & 0.77 & 0.5 & $.55-.78$ & $.30-.61$ \\
\hline 6. Market Responsive Agility & 0.84 & 0.8 & 0.67 & $.78-.85$ & $.61-.72$ \\
\hline 7. Sales Performance & 0.82 & 0.9 & 0.82 & $.89-.93$ & $.79-.86$ \\
\hline 8. Top Management Commitment ${ }^{a}$ & 0.92 & - & - & - & - \\
\hline
\end{tabular}

Note. ${ }^{a}$ Moderator is not included in the CFA as the moderating effect is assessed with nested model. Only Cronbach's a for moderator is reported.

checked in this study. Front-end functionality was modeled as a reflective second-order construct comprised of the two first-order dimensions: information and sales functions and customer-oriented functions. According to Jarvis et al. (2003), the first-order factors are complementary (i.e., they interact and covary with each other. The covariance of these two first-order factors is .55). A reflective second-order construct is appropriate for capturing complementarities (Tanriverdi and Venkatraman, 2005). The alternative ap- proach of using a formative second-order modeling is not appropriate because it does not assume any interactions or covariance among the first order dimensions of a higherorder construct (Chin, 1998).

Data fit the measurement model for front-end functionality well: $X^{2}(13)=31.566, X^{2} / \mathrm{df}=2.428$, $\mathrm{CFI}=.974, \mathrm{TLI}=.958, \mathrm{SRMR}=.05, \mathrm{RMSEA}=.06$. Respectively, Cronbach's $\alpha$, construct reliability, and variance extraction for Front-end Functionality are $\alpha=.81, \mathrm{CR}=.73$, and $\mathrm{VE}=.58$. As theorized in the Conceptual Model section, 
Building IT Capability to Increase Organizational Performance: A Path-Oriented Process / Bi et al.

front-end functionality is a higher-order construct comprising multiple dimensions with significant loadings (all $p$-values<.001). Paths from second-order constructs to first-order factors are of high magnitude, either nearing or exceeding a suggested cutoff value of .7 (Chin, 1998). Marsh and Hocevar (1985) suggested that the efficacy of second-order models should be assessed by the target coefficient ( $T$ ratio) with an upper bound of 1 . Our models display very high $T$ ratios approximating 1, implying that relationships among first-order constructs are sufficiently captured by their respective second-order construct (Stewart and Segars, 2002). Given solid theoretical and empirical grounds, and the parsimonious nature of the second-order factors (Hull et al., 1991), the conceptualization of front-end functionality as a high-order, multidimensional construct is considered justified.

\section{Result}

Given the acceptable measurement models, we estimated a full latent variable structural model (Anderson and Gerbing, 1988) using the same set of goodness of fit criteria to test our structural model and respective hypotheses. Table 5 summarizes the results of hypothesis testing, revealing reliable and robust fit between our theoretical model and sample covariances: $X^{2}(220)=414.057, X^{2} / d f=1.882<3$ (Carmines and Mclver, 1981), CFI=.947>.90 (Hair et al., 2006), TLI=.939>.90 (Hair et al., 2006), SRMR=.053<.06 (Hu and Bentler, 1999), and RMSEA $=.053<.08$ (Hair et al., 2006). These indices suggest a good fit. Table 5 shows that, except for $\mathrm{H}_{5}$ and $\mathrm{H}_{7}$, all hypothesized relationships are supported.

Figure 2 shows percentage of variance explained by the model for each endogenous variable. Squared multiple correlation (SMC) values, which are similar to multiple $R^{2}$ in multivariate regression analysis, show that the structural model accounts for $6 \%$ of variance in IT infrastructure in use, $42 \%$ of the variance in back-end integration, $68 \%$ of the variance in front-end functionality, $35 \%$ of the variance in market responsive agility, and $40 \%$ of the variance in sales performance.

\begin{tabular}{|l|l|l|}
\hline \multicolumn{1}{|c|}{ Hable 5. Hypotheses and Test Results } & \multicolumn{1}{c|}{$\begin{array}{c}\text { Standardized } \\
\text { Parameter } \\
\text { Estimate }\end{array}$} & \multicolumn{1}{c|}{ Conclusion } \\
\hline $\mathrm{H}_{1}:$ E-business Centric IT Expertise --> IT Infrastructure in Use & $.24^{* * *}$ & Supported \\
\hline $\mathrm{H}_{2}:$ E-business Centric IT Expertise --> Back-end Integration & $.56^{* * *}$ & Supported \\
\hline $\mathrm{H}_{3}:$ E-business Centric IT Expertise --> Front-end Functionality & $.23^{* *}$ & Supported \\
\hline $\mathrm{H}_{4}:$ IT infrastructure in Use --> Back-end Integration & $.21^{* * *}$ & Supported \\
\hline $\mathrm{H}_{5}:$ IT infrastructure in Use --> Front-end Functionality & -.10 & Not Supported \\
\hline $\mathrm{H}_{6}:$ Back-end Integration --> Front-end Functionality & $.68^{* * *}$ & Supported \\
\hline $\mathrm{H}_{7}:$ Back-end Integration --> Market Responsive Agility & -.19 & Not Supported \\
\hline $\mathrm{H}_{8}:$ Front-end Functionality --> Market Responsive Agility & $.74^{* *}$ & Supported \\
\hline $\mathrm{H}_{9}:$ Market Responsive Agility --> Sales Performance & $.63^{* * *}$ & Supported \\
\hline \begin{tabular}{l} 
Structural model goodness-of-fit indexes: \\
$\mathrm{X}^{2}(220)=414.057, \mathrm{X}^{2} / \mathrm{df}=1.882$, CFI=.947, TLI=.939, SRMR=.053, and RMSEA=.053. \\
\hline Note. ${ }^{*} p<.05 .{ }^{* *} p<.01 .{ }^{* * *} p<.001$.
\end{tabular} & \\
\hline
\end{tabular}




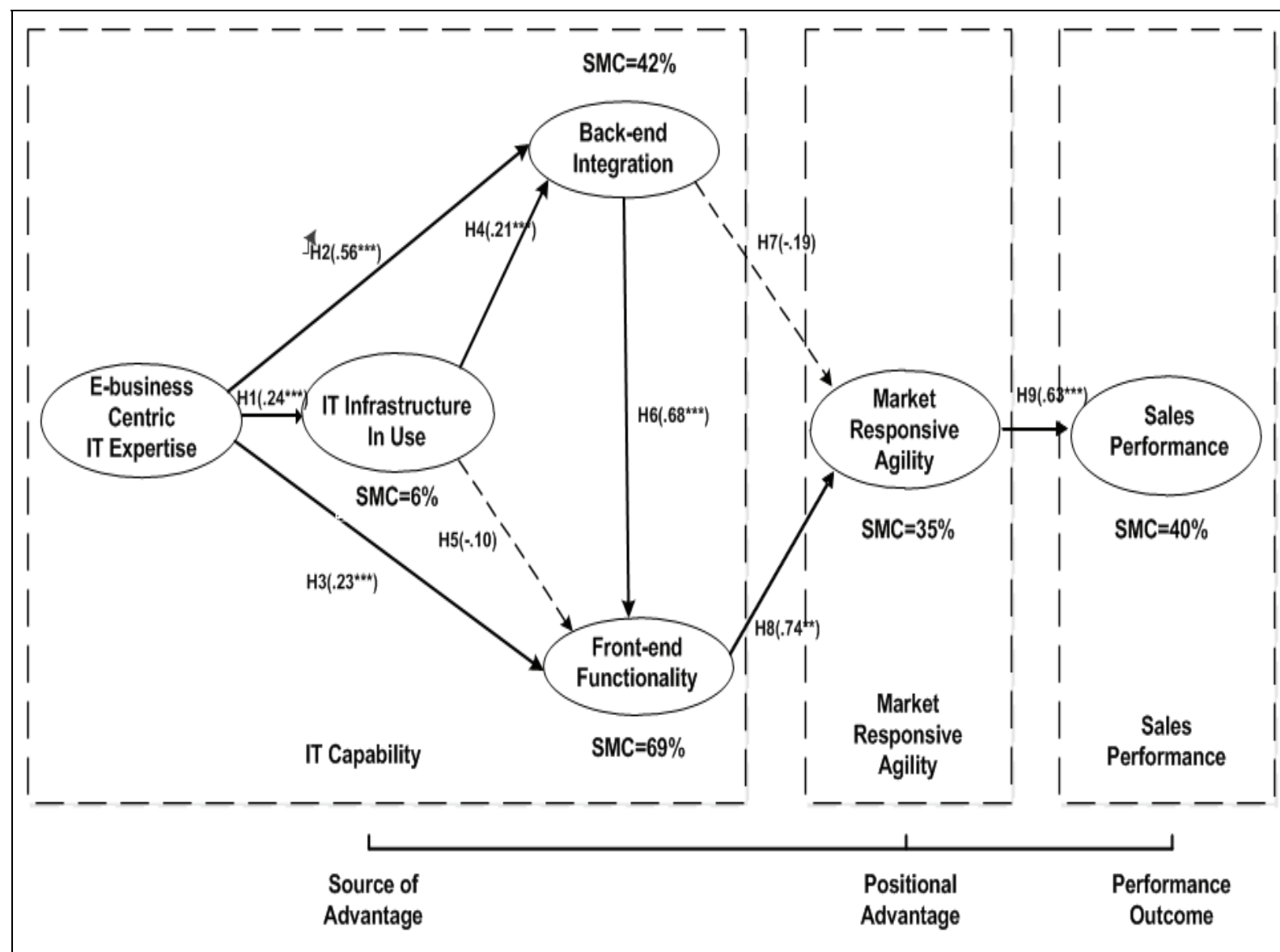

Figure 2 - Results for Final Full Structural Model

\begin{tabular}{|c|c|c|c|c|c|c|c|c|c|}
\multicolumn{9}{|c|}{ Table 6 - Results of Multi-group Analyses } \\
\hline & $\boldsymbol{X}^{\mathbf{2}}$ & df & CFI & TLI & RMSEA & $\begin{array}{c}\text { Model } \\
\text { Comparison }\end{array}$ & $\Delta \boldsymbol{X}^{\mathbf{2}}$ & $\Delta$ df & $\boldsymbol{p}$ \\
\hline M1 & 332.709 & 182 & .898 & .883 & .052 & & & & \\
\hline M2 & 343.218 & 183 & .892 & .876 & .053 & M2 vs M1 & 10.509 & 1 & $<.01$ \\
\hline M3 & 332.711 & 183 & .899 & .884 & .052 & M3 vs M1 & .001 & 1 & $>.05$ \\
\hline M4 & 334.087 & 183 & .898 & .883 & .052 & M4 vs M1 & 1.378 & 1 & $>.05$ \\
\hline
\end{tabular}

Note. M1=unconstrained model (all parameters free); M2=equal regression weights between ITEP and BI for low and high subsamples; M3=equal regression weights between ITEP and ITIF for low and high sub-samples; M4=equal regression weights between ITEP and FF for low and high sub-samples.

The moderating effects of TMC on relationships between e-business centric IT expertise and back-end Integration, IT infrastructure in use, and front-end functionality $(\mathrm{H} 10, \mathrm{H} 11$, $\mathrm{H} 12$ ) were tested using multi-group analyses. We divided our data into two sub-samples (i.e., low and high TMC groups), based on the median scores of TMC. The difference between the mean TMC score of the two subsamples was tested using t-test to ensure statistical significance, which was confirmed $(p<.01)$. $X^{2}$ difference tests were subsequently employed to assess statistical significance between the low and high TMC groups on three paths: between e-business centric IT expertise and back-end integration, between e-business centric IT expertise and IT infrastructure in use, and between e-business centric IT expertise and front-end functionality. The test results reveal that higher level of 
TMC increases the positive link between IT expertise and back-end integration. However, TMC was not found to have any significant influence on the links between e-business centric IT expertise and IT infrastructure in use, and e-business centric IT expertise and front-end functionality (Table 6).

Our test results also show that none of the three control variables appear to exert any significant effect on sales performance in our model, despite their expected influence on sales performance.

\section{Assessment of an Alternative Model}

The hypothesized relationships of the proposed research model are grounded on the premise that IT capability development follows a path dependent process, initiated by a distinctive set of attributes - e-business centric IT expertise - endemic to a firm's IT human resource endowment. The proposed research model views e-business centric IT expertise as the transformation agent driving the selection and use of appropriate IT infrastructure as well as the development of backend integration and front-end functionality to achieve market responsive agility.

An alternative theoretically plausible view of IT capability development posits that ebusiness centric IT expertise, IT infrastructure in use, back-end integration, and front-end functionality, as a bundle of valuable, rare, inimitable and hard-to-substitute resources, jointly contribute to the development of market responsive agility. In short, the alternative model views the four constructs as direct antecedents of market responsive agility, ignoring the possible causal linkages between them. This model is founded on the premise that each of the four constructs is a key building block of organizational IT capability. This alternative conceptualization thus does not subscribe to the notion that IT capability is developed through a unique combination of IT resources.

The alternative model contains five paths: one each from the four constructs to market responsive agility, which drives sales perfor- mance. This alternative model and its results (standardized path coefficients) are shown in Figure 3 . The model fit indices for the alternative model $\left(X^{2}(218)=411.388, \quad X^{2} / \mathrm{df}=1.887\right.$, CFI=.947, TLI $=.938, \quad$ SRMR $=.052$, and RMSEA $=.054$ ) are comparable to those of the proposed model. However, three of the five hypotheses in the alternative model were found to be insignificant. It suggests that ebusiness centric IT expertise, IT infrastructure in use, and back-end integration do not contribute directly to building market responsive agility. The result thus lend support to the notion that the four IT resources do not act independently to create market responsive agility.

\section{Mediation Tests}

The resulting structural model depicted in Figure 2 indicates that IT infrastructure in use, back-end integration, front-end functionality, and market responsive agility serve as mediators in channelling the effect of e-business centric IT expertise on sales performance. Given that our focus is on how the four IT resource constructs - e-business centric IT expertise, IT infrastructure in use, back-end integration, and front-end functionality - are combined to build IT capability, the structural model of Figure 2 suggests that IT capability is developed through a path-specific process directed by e-business centric IT expertise. Verge and Durand (2010) suggested that mediation techniques, among others, offer a systematic means of exploring data to exhaust "the condition sets that prevail in defined path-dependence situations" (p. 751). We view path-specificity as a "diluted" version of path-dependence. Drawing on the suggestion of Verge and Durand (2010), we utilized mediation test as a means to demonstrate the existence of path-specificity.

To validate the mediating roles of IT infrastructure in use, back-end integration, frontend functionality, and market responsive agility, five additional models were tested (see Figures 4 to 8 ). These five models were designed to check whether the relationships among the six constructs in our structural model of Figure 2 satisfy the four conditions 
Building IT Capability to Increase Organizational Performance: A Path-Oriented Process / Bi et al.

outlined in Baron and Kenny (1986) for the existence of mediation effect. The first model (Figure 4) confirms that e-business centric IT expertise has a significant effect on sales performance, satisfying the first condition stipulated by Baron and Kenny (1986), i.e., the independent variable influences the dependent variable. The second to fifth models (Figures 5 to 8 ) successively test each of the mediators - market responsive agility, front-end functionality, back-end integration, and IT infrastructure in use - to determine whether they meet conditions 2 to 4 stated in Baron and Kenny (1986), i.e., whether the independent variable (e-business centric IT expertise) influences the mediator (Condition 2); whether the mediator influences the dependent variable (sales performance) (Condition 3 ); and whether the effect of the independent variable (e-business centric IT expertise) on the dependent variable (sales performance) diminishes after controlling for the effects of the mediator (Condition 4). As revealed in Figures 4 to 8 , all four conditions were fully met for all four mediators, confirming the mediating roles of IT infrastructure in use, backend integration, front-end functionality, and market responsive agility. More importantly, the mediation test results support the notion that IT capability development follows a pathspecific process.

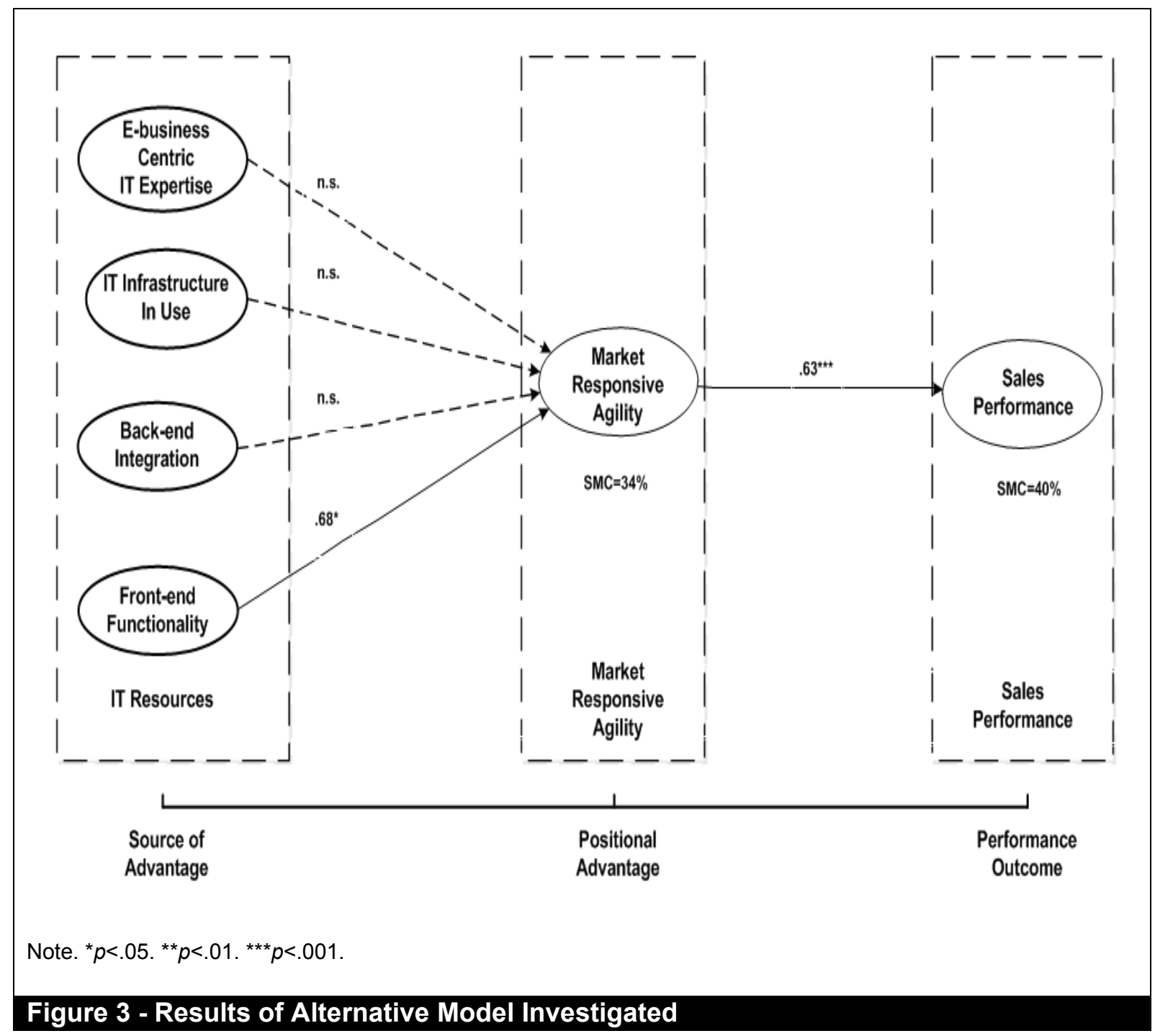



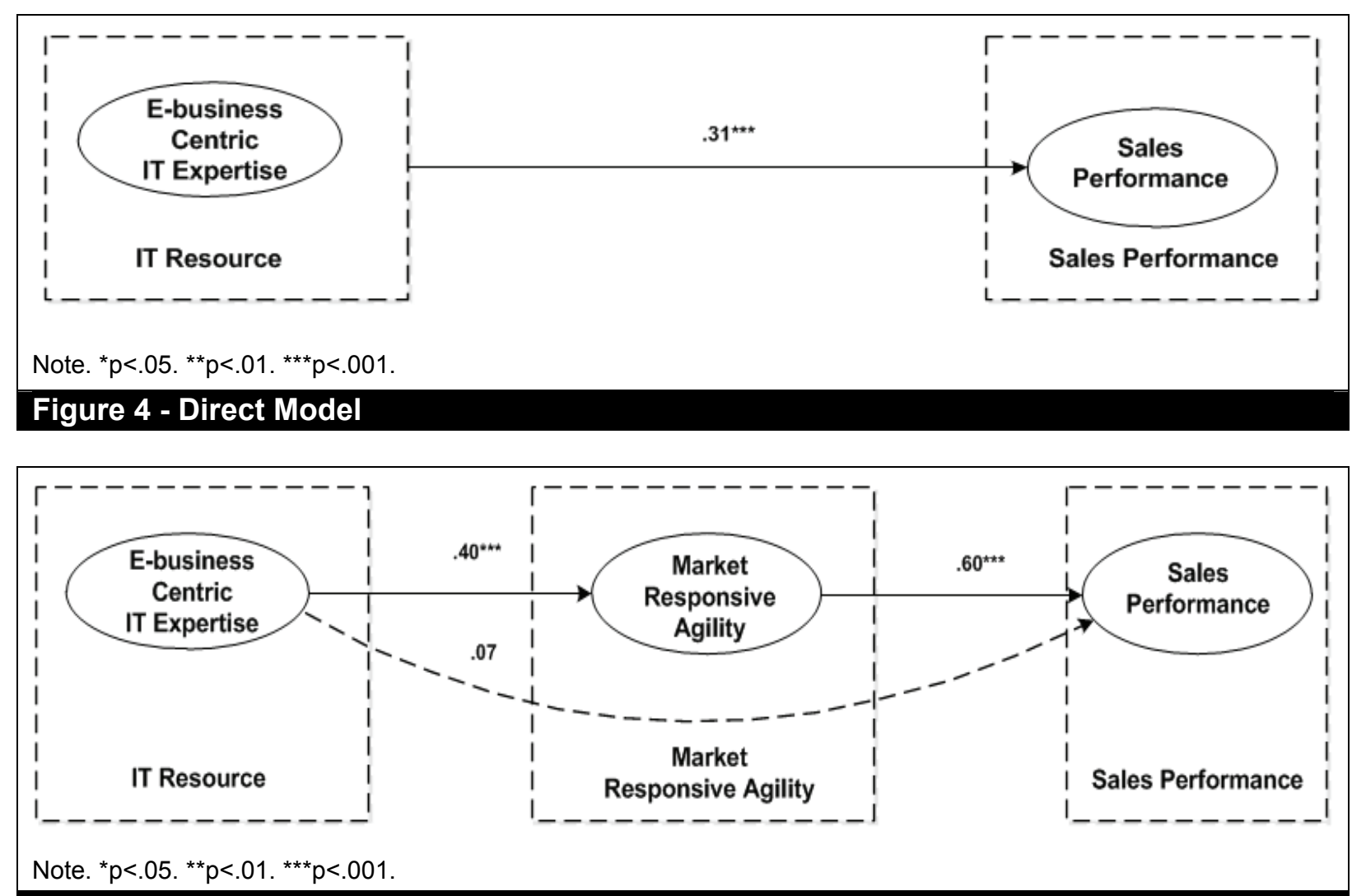

Figure 5 - Mediated Model with Market Responsive Agility

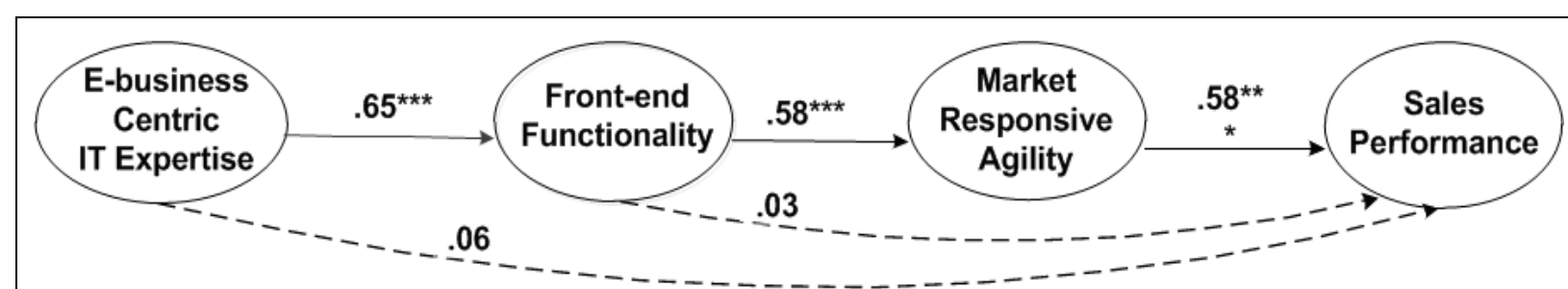

Note. ${ }^{*} p<.05 .{ }^{* *} p<.01 .{ }^{* * *} p<.001$.

Figure 6 - Mediated Model with Market Responsive Agility and Front-end Functionality

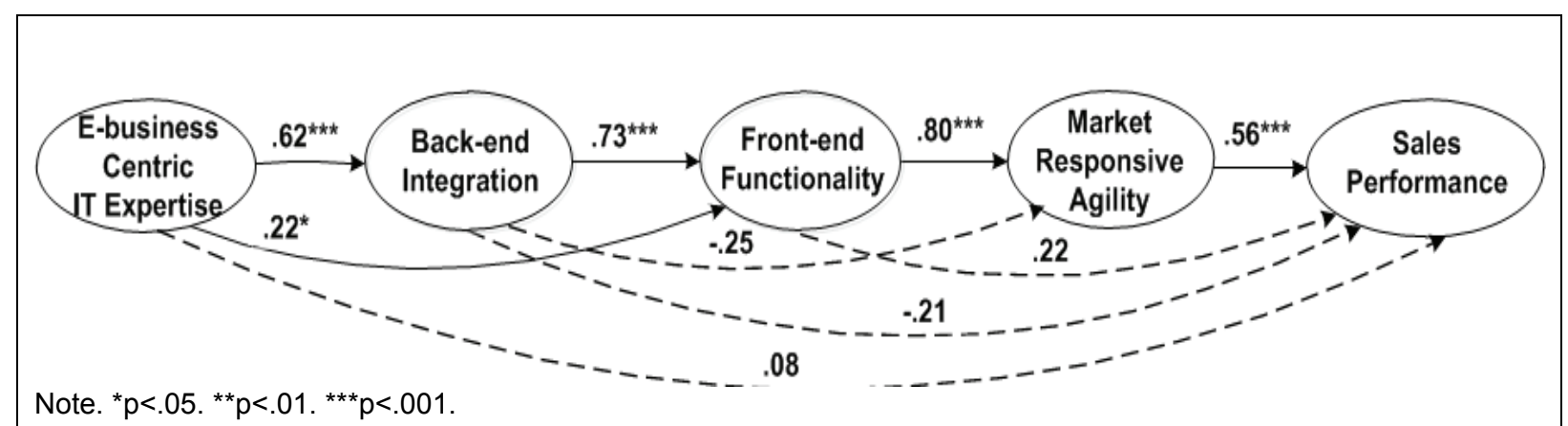

Figure 7 - Mediated Model with Market Responsive Agility, Front-end Functionality, and Back-end Integration 


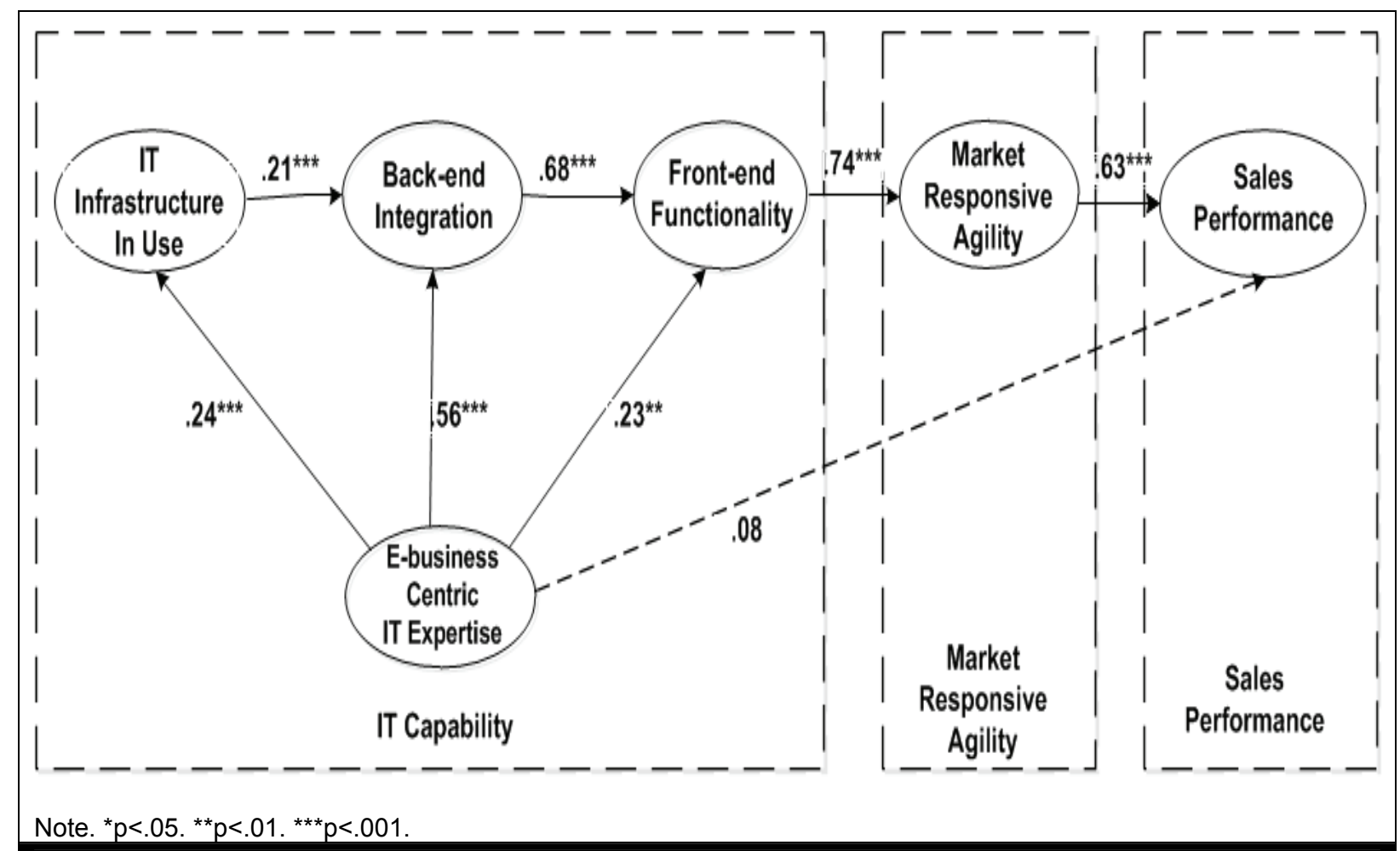

Figure 8 - Mediated Model with Market Responsive Agility, Front-end Functionality, Backend Integration, and IT Infrastructure in Use

\section{Discussion and Conclusion}

This study sets out to investigate IT capability as a network of tightly-linked constructs driven by the use of e-business centric IT expertise to identify and select appropriate IT infrastructure to develop a task-oriented back-end and a user-friendly multifunctional front-end. We tested the linkages between the constructs that form IT capability and also their joint-effects on market responsive agility and sales performance using data drawn from a survey of 310 fast-growth SMEs in Australia. Our findings, based on the hypotheses that are supported, the results of the alternative model investigated as well as the mediation tests conducted, confirm that IT capabilitybuilding follows a path-specific process, as Figure 2 (and Figure 8) indicates. IT infrastructure in use, back-end integration, and front-end functionality are three indispensable parts of the IT capability-building chain. The extent to which the three can be harnessed into an advantage-generating capability depends considerably on the quality of a firm's
IT human resources (e-business centric IT expertise). The contribution of TMC in this capability-building process is that it enhances the effect that e-business centric IT expertise has on back-end integration.

\section{Contribution to IS Literature}

Our findings offer a number of insights that broaden current understanding on the creation of IS capabilities, as manifested in the path-specific process of IT capability development based on our sample of fast-growth SMEs. These findings contribute to IT business value literature in six major aspects. First, they confirm the lynchpin role of ebusiness centric IT expertise, accentuating the importance of IT human resources, in addition to IT skills, in developing IS capabilities.

Second, IT infrastructure in use, though an essential platform for IT systems and application development, has no direct effect in contributing to enhancing the value of front-end functionality. While this finding reaffirms the commodity nature of IT infrastructure in use 
Building IT Capability to Increase Organizational Performance: A Path-Oriented Process / Bi et al.

that others have noted (Clemons and Row, 1991; Zhu and Kraemer, 2005), it highlights the indispensable role IT infrastructure plays in providing an appropriate technological platform for the development of back-end integration. It suggests that IT infrastructure remains a key component of the IT resource bundle that contributes to the development of superior IT capability. The path-specific process of IT capability-building further indicates that the quality of the IT infrastructure in use will influence not only the way back-end integration would be developed but how well it could be developed. From the IT investment perspective, this finding shows that selecting an appropriate set of IT infrastructure is one of the first step toward building a robust back-end integration and superior IT capability.

Third, back-end integration plays an important bridging role in linking IT infrastructure in use to front-end functionality, but has no direct effect on market responsive agility. This finding underscores the criticality of back-end integration as a feature that differentiates a firm's IT capability from those of competitors. Because the development of back-end integration is a causality ambiguous process, the manner in which e-business centric IT expertise contributes to the development of back-end integration becomes an inimitable operation. As Zhu and Kraemer (2005) rationalize, back-end integration is "often tailored to a firm's strategic context and is woven into the organization's fabric, which is not transparent to competitors" (p. 78).

Fourth, while previous studies (Zhu and Kraemer, 2005) have dismissed the rare, valuable, non-substitutable, and hard-to-replace properties of front-end functionality due to its ubiquitous appearance in commercial websites, the finding in this study suggests that front-end functionality has not lost all its shines. The path-specific IT capabilitybuilding process revealed in this study shows that front-end functionality is the face of an organization - it provides the only connection that IT capability has with market responsive agility. Modeled as a second order construct, our results indicate that the representation of front-end functionality needs to take into con- sideration the customer-oriented aspects, which differ between companies. In short, front-end functionality is a necessary, though insufficient, part of the IT capability-building process. Front-end functionality serves as the mediator that channels the effect of back-end integration in supporting market responsive agility. In sum, on its own, front-end functionality may no longer be a resource that could provide a competitive edge to the firm. In combination with back-end integration and IT infrastructure in use, however, front-end functionality creates the synergistic effect expected of a well-integrated IT system: it enables the IT skills, business knowledge and experience of a firm's IT personnel to create market responsive agility to gain sales.

Fifth, the significance of TMC as a moderator on the positive link between e-business centric IT expertise and back-end integration underscores the importance of TMC as a valueadded dimension of the IT capability-building process. TMC gives the extra edge - the intangible moral support among others - the IT team needs in weaving the back-end integration into the organizational fabrics.

Lastly, since our model is tested using data drawn from a sample consisting exclusively of fast-growth SMEs, we conclude that fastgrowth SMEs develop their IT capability via a path-specific process anchored by their ebusiness centric IT expertise to achieve market responsive agility and gain sales. Worded differently, we interpret that one of the basic ingredients for growth among fast-growth SMEs is their ability to leverage their IT resources in a synergistic manner to produce superior IT capability.

\section{Implications for Practitioners}

The results of this study have important implications for practitioners. Our findings that IT capability building follows a path-specific process driven by a firm's e-business centric IT expertise confirm the distinctive roles of each of the four IT resources examined. Therefore, while some IT resources, such as IT infrastructure, by itself, might not offer a source of differential advantage, these resources are, in Clemons and Row (1991) words, "competitive 
Building IT Capability to Increase Organizational Performance: A Path-Oriented Process / Bi et al.

necessities": their absence would lead to a competitive disadvantage. The implication flowing from this argument suggests that investment in IT resources requires a holistic and integrated approach. The complementary functions of different IT resources have to be noted. For instance, it may be unwise for an organization to develop streamline ebusiness processes to integrate the operations of different business units without having completed an assessment of the support capability of IT infrastructure in use. Equally, increasing front-end functionalities to enhance its attractiveness to customers may be inapt without a corresponding assurance that the disparate databases housed in the backend are capable of servicing those needs. In short, the path-specific process involved in IT capability building suggests that piecemeal investment in IT resources could turn out to be counter-productive.

Second, our findings reaffirm IT capability is a source of advantage, enabling firms to create market responsive agility (a positional advantage) to gain superior sales performance. This finding further underscores the importance of understanding the antecedentprecedent relationships between different types of IT resources to ensure that IT investment would yield the benefits envisaged.

Third, our study illustrates the critical role of TMC in nurturing information capability within organizations. The significant moderating effect that TMC has on the causal link from ebusiness centric IT expertise to back-end integration supports Rai et al.'s (2006) argument that senior management commitment could foster the development of distinctive IS capabilities that form part of corporate strategies and drive growth.

Lastly, with a growing interest in investigating the performance determinants of fast-growth firms (Moreno and Casillas, 2008), our study provides an alternative lens from a technology usage perspective. Our findings offer an integrative framework for SME managers to understand how their IT investments may be put to use in a productive and beneficial way to create competitive advantage and achieve rapid growth through sales.

\section{Limitations and Future Research}

This study has a number of methodological and conceptual limitations that should be acknowledged. First, we have used a static cross-sectional research design by collecting data at a single point in time. This makes it difficult to address issues of dynamic IS capability development over a run of several years. Future studies may consider examining "state changes" over longer periods of time to increase our understanding of the developmental paths involved in IT capabilitybuilding and leveraging to enhance operational performance.

Second, we have relied on the use of singleinformant in data collection which is always susceptible to reporting bias. The use of multiple methods of measurement to alleviate any potential reporting bias ought to be given due consideration in future studies.

Third, our sample is confined exclusively to fast-growth SMEs. This creates comparative and generalization issues when interpreting the findings. For instance, whether IT capability is a feature distinctive of fast-growth SMEs that have afforded them a competitive edge in developing superior operational attributes, such as flexibility, responsiveness, and agility, remain unanswered.

Fourth, in examining the effects that IT capability has on market responsive agility and sales performance, we have not been able to account for the effect of one very important factor - the entrepreneurial capabilities of fast-growth SMEs. Given that fast-growth SMEs are less risk-averse than other SMEs and have other specific entrepreneurial characteristics (e.g., entrepreneurial orientation) that drive their growth (Barringer et al., 2005), the endogeneity of these factors needs to be taken into consideration in future studies.

Lastly, this study only examines IT capability, as one of many IS capabilities, from IT human resource and IT infrastructure perspectives. It has not included many other organizational factors that do contribute to the build- 
Building IT Capability to Increase Organizational Performance: A Path-Oriented Process / Bi et al.

ing of IS capabilities, as pointed out by Wade and Hulland (2004). In addition, the integration of IS competence into other operational capabilities to meet changing market realities would form an intriguing line of inquiry. As we evolve in our understanding of the causal links between IS capabilities and business

\section{References}

Anderson, J. C. and D. W. Gerbing (1988). "Structural Equation Modeling in Practice: A Review and Recommended Two-Step Approach," Psychological Bulletin, 103(3), 411-423.

Armstrong, C. P. and V. Sambamurthy (1999). "Information Technology Assimilation in Firms: The Influence of Senior Leadership and IT Infrastructures," Information Systems Research 10(4), 304-327.

Armstrong, J. S. and T. S. Overton (1977). "Estimating Nonresponse Bias in Mail Surveys," Journal of Marketing Research 14(3), 396-402.

Ballard, R. (1992). "Short Forms of the Marlowe-Crowne Social Desirability Scale," Psychological Reports 71(3), 1155-1160.

Barney, J. B. (1991). "Firm Resources and Sustained Competitive Advantage," Journal of Management, 17(1), 99120.

Baron, R. M. and D. A. Kenny (1986). "The Moderator-Mediator Variable Distinction in Social Psychological Research:Conceptual, Strategic and Statistical Considerations," Journal of personality and social psychology, 51 (6), 1173-1182.

Barringer, B. R., F. F. Jones, and D. O. Neubaum (2005). "A Quantitative Content Analysis of the Characteristics of Rapid-Growth Firms and Their Founders," Journal of Business Venturing, 20(5), 663-687.

Barua, A. and T. Mukhopadhyay (2000). Information Technology and Business performance, examining the complementary relationships between IS competence and other organizational capabilities can cast further insights into many IT-dependent organizational routines that create value and enhance performance.

Performance: Past, Present and Future, in R. W. Zmud (Ed.) Framing the Domains of It Management: Projecting the Future through the Past, Pinnaflex Educational Resources, Inc Cincinnati, Oh, 65-84.

Bharadwaj, A. S. (2000). "A Resource-Based Perspective on Information Technology Capability and Firm Performance: An Empirical Investigation," MIS Quarterly, 24(1), 169-196.

Bharadwaj, A. S., S. C. Bharadwaj, and B. R. Konsynski (1999). "Information Technology Effects on Firm Performance as Measured by Tobin's Q," Management Science, 45(7), 1008-1024.

Bhatt, G. D. and V. Grover (2005). "Types of Information Technology Capabilities and Their Role in Competitive Advantage: An Empirical Study," Journal of Management Information Systems 22(2), 253-277.

Brynjolfsson, E. and L. Hitt (1998). "Beyond the Productivity Paradox: Computers Are the Catalyst for Bigger Changes," Communications of the ACM, 41(8), 49-55.

Brynjolfsson, E. and L. M. Hitt (2000). "Beyond Computation: Information Technology, Organizational Transformation and Business Performance," Journal of Economic Perspectives, 14(4), 2348.

Carmines, E. G. and S. P. Mclver (1981). Analyzing Models with Unobserved Variables, in G. W. Bohrnstedt and E. F. Borgatta (Eds.) Social Measurement: Current Issues, Beverly Hills: Sage. 
Building IT Capability to Increase Organizational Performance: A Path-Oriented Process / Bi et al.

Carr, N. G. (2003). "IT Doesn't Matter," Harvard Business Review, 81(5), 41-49.

Chatterjee, D., R. Grewal, and V. Sambamurthy (2002) "Shaping up for ECommerce: Institutional Enablers of the Organizational Assimilation of Web Technologies," MIS Quarterly, 26(2), 65-89.

Chin, W. W. (1998). "Issues and Opinion on Structural Equation Modeling," MIS Quarterly, 22(1), 1-10.

Clark, C. E., N. C. Cavanaugh, C. V. Brown, and V. Sambamurthy (1997). "Building Change-Readiness Capabilities in the Is Organization: Insights from the Bell Atlantic Experience," MIS Quarterly, 21(4), 425-455.

Clemons, E. K. and M. C. Row (1991). "Sustaining IT Advantage: The Role of Structural Differences," MIS Quarterly (3), 275-292.

Cohen, M. D. and D. A. Levinthal (1990). "Absorptive Capacity: A New Perspective on Learning and Innovation," Administrative Science Quarterly, 35, 128-152.

Cooper, R. B. and R. W. Zmud (1990). "Information Technology Implementation Research: A Technological Diffusion Approach," Management Science, 36 (2), 123-139.

Damanpour, F. (1991). "Organizational Innovation: A Meta-Analysis of Effects of Determinants and Moderators," Academy of Management Journal, 34(3), 555-590.

Day, G. S. (1994). "The Capabilities of Market-Driven Organizations," Journal of Marketing, 58(4), 37-52.

Day, G. S. and R. Wensley (1988). "Assessing Advantage: A Framework for Diagnosing Competitive Superiority," Journal of Marketing, 52(2), 1-20.
Dehning, B., V. Richardson, and R. Zmud (2003). "The Value Relevance of Announcements of Transformational Information Technology Investments," MIS Quarterly, 27(4), 637-656.

Dehning, B., V. J. Richardson, and R. W. Zmud (2007). "The Financial Performance Effects of IT-Based Supply Chain Management Systems in Manufacturing Firms," Journal of Operations Management, 25(4), 806-824.

Dierickx, I. and K. Cool (1989). "Asset Stock Accumulation and Sustainability of Competitive Advantage," Management Science, 35(12), 1504-1511.

Dobbs, M. and R. T. Hamilton (2007). "Small Business Growth: Recent Evidence and New Directions," International Journal of Entrepreneurial Behaviour \& Research, 13(5), 296-322.

Dong, S., S. X. Xu, and K. Zhu (2009). "Information Technology in Supply Chain: The Value of IT-Enabled Resources under Competition," Information Systems Research, 20(1), 18-32.

Eikebrokk, T. R. and D. H. Olsen (2007). "An Empirical Investigation of Competency Factors Affecting E-Business Success in European Smes," Information \& Management, 44(4), 364-383.

Fichman, R. G. (1992). Information Technology Diffusion: A Review of Empirical Research. Proceedings of the 13th International Conference on Information Systems, Dallas, Texas, 195-206.

Fink, L. and S. Neumann (2007). "Gaining Agility through IT Personnel Capabilities: The Mediating Role of IT Infrastructure Capabilities," Journal of the Association for Information Systems, 8(8), 440-462.

Fornell, C. and D. F. Larcker (1981). "Evaluating Structural Equation Models with Unobservable Variables and Measurement Error," Journal of Marketing Research, 18(1), 39-50. 
Building IT Capability to Increase Organizational Performance: A Path-Oriented Process / Bi et al.

Fraboni, M. and D. Cooper (1989). "Further Validation of Three Short Forms of Marlowe-Crowne Scale of Social Desirability," Psychological Reports, 65(2), 595-600.

Gefen, D., D. W. Straub, and M. C. Bourdreau (2000). "Structural Equation Modeling and Regression: Guidelines for Research Practices," Communications of the AIS, 4(7), 1-78.

Hair, J. F., W. C. Black, B. J. Babin, R. E. Anderson et al. (2006). Multivariate Data Analysis. New Jersey: Prentice Hall.

Helfat, C. E. and M. A. Peteraf (2003). "The Dynamic Resource-Based View: Capability Lifecycles," Strategic Management Journal, 24(10), 997.

Hernández-Espallardo, M. and N. Arcas-Lario (2003). "The Effects of Authoritative Mechanisms of Coordination on Market Orientation in Asymmetrical Channel Partnerships," International Journal of Research in Marketing, 20(2), 133-152.

Hu, L. and P. M. Bentler (1999). "Cutoff Criteria for Fit Indexes in Covariance Structure Analysis: Conventional Criteria Versus New Alternatives," Structural Equation Modeling, 6, 1-55.

Hull, J. A., J. C. Tedlie, and D. A. Lehn (1991). Structural Equation Modeling: Concepts, Issues and Applications, in R. $\mathrm{H}$. Hoyle (Ed.) Structural Equation Modeling: Concepts, Issues and Applications, London: Sage.

Jarvis, C. B., S. B. Mackenzie, and P. M. Podsakoff (2003). "A Critical Review of Construct Indicators and Measurement Model Misspecification in Marketing and Consumer Research," Journal of Consumer Research, 30(2), 199-218.

Jöreskog, K. G. (1978). "Structural Analysis of Covariance and Correlation Matrices," Pschometrika, 43(4), 443-487.
Kearns, G. S. and A. L. Lederer (2003). "A Resource-Based View of Strategic IT Alignment: How Knowledge Sharing Creates Competitive Advantage," Decision Sciences, 34(1), 1-29.

Keen, P. G. W. (1991). Shaping the Future: Business Design through Information Technology. Cambridge, MA: Harvard Business Press.

Kim, D., S. T. Cavusgil, and R. J. Calantone (2006). "Information System Innovations and Supply Chain Management: Channel Relationships and Firm Performance," Journal of the Academy of Marketing Science, 34(1), 40-54.

Kuan, K. K. Y. and P. Y. K. Chau (2001). "A Perception-Based Model for Edi Adoption in Small Businesses Using a Technology-Organization-

Environment Framework," Information \& Management, 38(8), 507-521

Lewis, I. (2001). "Logistics and Electronic Commerce: An Interorganizational Systems Perspective," Transportation Journal, 40(4), 5-13.

Lin, H. F. and S. M. Lin (2008). "Determinants of E-Business Diffusion: A Test of the Technology Diffusion Perspective," Technovation, 28, 135-145.

Makadok, R. (2001) "Toward a Synthesis of the Resource-Based and DynamicCapability Views of Rent Creation," Strategic Management Journal, 22(5), 387-401.

Marlowe, D. and D. P. Crowne (1961). "Social Desirability and Response to Perceived Situational Demands," Journal of Consulting Psychology, 25, 109115.

Marsh, H. and D. Hocevar (1985). "A New, More Powerful Approach to MultitraitMultimethod Analyses: Application of Second-Order Confirmatory Factor Analysis," Journal of Applied Psychology, 73(1), 107-117. 
Building IT Capability to Increase Organizational Performance: A Path-Oriented Process / Bi et al.

Mata, F. J., W. L. Fuerst, and J. B. Barney (1995). "Information Technology and Sustained Competitive Advantage: A Resource-Based Analysis," MIS Quarterly, 19(4), 487-505.

Mishra, A. N. and R. Agarwal (2009). "Technological Frames, Organizational Capabilities, and IT Use: An Empirical Investigation of Electronic Procurement," Information Systems Research (Articles in Advance), 1-22.

Moreno, A. M. and J. C. Casillas (2008). "Entrepreneurial Orientation and Growth of Smes: A Causal Model," Entrepreneurship: Theory \& Practice, 32(3), 507-528.

Nunnally, J. C. and I. H. Bernstein (1994). Psychometric Theory. New York: McGraw Hill.

Petter, S., D. Straub, and A. Rai (2007). "Specifying Formative Constructs in Information Systems Research," MIS Quarterly, 31(4), 623-656.

Podsakoff, P. M., S. B. MacKenzie, J.-Y. Lee, and N. P. Podsakoff (2003). "Common Method Biases in Behavioral Research: A Critical Review of the Literature and Recommended Remedies," Journal of Applied Psychology, 88(5), 879-903.

Radjou, N. (2003). "U.S. Manufacturers' Supply Chain Mandate," World Trade, 16(2), 42-46.

Rai, A., R. Patnayakuni, and N. Seth (2006). "Firm Performance Impacts of Digitally Enabled Supply Chain Integration Capabilities," MIS Quarterly, 30(2), 225246.

Ravinchandran, T. and C. Lertwongsatien (2005). "Effect of Information Systems Resources and Capabilities on Firm Performance: A Resource-Based Perspective," Journal of Management Information Systems, 21(4), 237-276.
Raymond, L. and F. Bergeron (2008). "Enabling the Business Strategy of SMEs through E-Business Capabilities: A Strategic Alignment Perspective," Industrial Management \& Data, 108(5), 577-595.

Rogers, E. M. (1995). Diffusion of Innovations. New York: Free Press.

Ross, J. W., C. M. Beath, and D. L. Goodlue (1996). "Developing Long-Term Competitiveness through It Assets," Sloan Management Review, 38(1), 31-45.

Sambamurthy, V., A. Bharadwaj, and V. Grover (2003). "Shaping Agility through Digital Options: Reconceptualizing the Role of Information Technology in Contemporary Firms," MIS Quarterly, 27(2), 237-263.

Sanders, N. R. (2008). "Pattern of Information Technology Use: The Impact on Buyer-Suppler Coordination and Performance," Journal of Operations Management, 26(3), 349-367.

Stank, T. P., S. B. Keller, and P. J. Daugherty (2001). "Supply Chain Collaboration and Logistical Service Performance," Journal of Business Logistics, 22(1), 29-47.

Stewart, K. A. and A. H. Segars (2002). "An Empirical Examination of the Concern for Information Privacy Instrument," Information Systems Research, 13(1), 36-49.

Straub, D. W. (1989). "Validating Instruments in MIS Research," MIS Quarterly, 13(2), 147-169.

Tanriverdi, H. and N. Venkatraman (2005). "Knowledge Relatedness and the Performance of Multibusiness Firms," Strategic Management Journal, 26(2), 97-119.

Teece, D. J., G. Pisano, and A. Shuen (1997) "Dynamic Capabilities and Strategic Management," Strategic Management Journal, 18(7), 509-533. 
Building IT Capability to Increase Organizational Performance: A Path-Oriented Process / Bi et al.

Teece, D. J. (2007). "Explicating Dynamic Capabilities: The Nature and Microfoundations of (Sustainable) Enterprise Performance " Strategic Management Journal, 28(13), 1319-1350.

Thompson, E. R. and F. T. T. Phua (2005). "Reliability among Senior Managers of the Marlowe-Crowne Short-Form Social Desirability Scale," Journal of Business and Psychology, 19(4), 541554.

Thong, J. Y. L. (1999). "An Integrated Model of Information Systems Adoption in Small Businesses," Journal of Management Information Systems, 15(4), 187-214.

Vergne, J.-P. and R. Durand (2010). "The Missing Link between the Theory and Empirics of Path Dependence: Conceptual Clarification, Testability Issue, and Methodological Implications," Journal of Management Studies, 47(4), 736-759.

Wade, M. and J. Hulland (2004). "Review: The Resource-Based View and Information Systems Research: Review, Extension, and Suggestions for Future Research," MIS Quarterly, 28(1), 107142.

Werts, C., R. Linn, and K. Jöreskog (1974). "Interclass Reliability Estimates: Testing Structural Assumptions," Educational and Psychological Measurement, 34(1), 25-33.

Wu, F., V. Mahajan, and S. Balasubramanian (2003). "An Analysis of E-Business Adoption and Its Impact on Business Performance," Journal of the Academy of Marketing Science, 31(4), 425447.
Wu, F., S. Yeniyurt, D. Kim, and S. T. Cavusgil (2006). "The Impact of Information Technology on Supply Chain Capabilities and Firm Performance: A Resource-Based View," Industrial Marketing Management, 35(4), 493504.

Zhu, K. (2004). "The Complementarity of Information Technology Infrastructure and E-Commerce Capability: A Resource-Based Assessment of Their Business Value," Journal of Management Information Systems, 21(1), 167-202.

Zhu, K., K. Kraemer, and S. Xu (2003). "Electronic Business Adoption by European Firms: A Cross-Country Assessment of the Facilitators and Inhibitors," European Journal of Information Systems, 12(4), 251-268.

Zhu, K. and K. L. Kraemer (2002). "ECommerce Metrics for Net-Enhanced Organizations: Assessing the Value of E-Commerce to Firm Performance in the Manufacturing Sector," Information Systems Research, 13(3), 275-295.

Zhu, K. and K. L. Kraemer (2005). "PostAdoption Variations in Usage and Value of E-Business by Organizations: Cross-Country Evidence from the Retail Industry," Information Systems Research, 16(1), 61-84.

Zhu, K., K. L. Kraemer, S. Xu, and J. Dedrick (2004). "Information Technology Payoff in E-Business Environments: An International Perspective on Value Creation of E-Business in the Financial Services Industry," Journal of Management Information Systems, 21(1), 17-54. 
Building IT Capability to Increase Organizational Performance: A Path-Oriented Process / Bi et al.

\begin{abstract}
About Authors
Rui Bi is a PhD student, Research Associate and Associate Lecturer at RMIT University, Australia. Rui's research interests include ebusiness and IT business value, supply chain management, and fast growth small-tomedium enterprises (SMEs), having published her work in a number of journals and presented her research at international conferences.
\end{abstract}

Booi H. Kam is an Associate Professor in the School of Business IT and Logistics, RMIT University, Australia. Booi has published in a diverse range of disciplines, including supply chain risk management, accident analysis, emarketing, transport and land use planning, postgraduate research supervision, and survey research. He also consults extensively in the Asia-Pacific Region, having participated in a range of multidisciplinary projects funded by the World Bank, the Asian Development Bank, and national and state governments in Asia.
Kosmas X. Smyrnios holds the position of Professor in the School of Management, at RMIT University, Australia. Kosmas is Foundation Associate Editor of the Journal of Family Business Strategy and was formerly an Associate Editor of Family Business Review and Foundation Board Member of the International Family Enterprise Research Academy (IFERA). Since the awarding of his PhD, Kosmas has developed an extensive applied research record across a number of disciplines, including marketing, psychology, physics, management, and accounting. Kosmas has established international credentials in the family business and SME areas, having been involved in a number of prominent national and international research projects. Kosmas is a recipient of almost \$2 million in research funding and has undertaken a number of consultancies for major multinational organizations including the Commonwealth Bank, Price Waterhouse Coopers, $\mathrm{BDO}, \mathrm{MGi}$, and $\mathrm{AXA}$. $\mathrm{He}$ is also frequently called upon to provide expert media commentary on SMEs. 